\title{
Economic Inequality and Political Responsiveness: A Systematic Review
}

\author{
Mads Andreas Elkjær and Michael Baggesen Klitgaard
}

\begin{abstract}
Do political outcomes respond more strongly to the preferences of the rich? In an age of rising inequality, this question has become increasingly salient. Yet, although an influential literature has emerged, no systematic account exists either of the severity of differentials in political responsiveness, the potential drivers of those differentials, or the variation across democracies. This article fills that gap. We analyze 1,163 estimates of responsiveness from 25 studies and find that, although this research collectively suggests that political outcomes better reflect the preferences of the rich, results vary considerably across models and studies. The divergence in results is partly driven by partisanship and the model specification, while we find no significant variation across either policy domains or general/specific measures of political outcomes. Finally, and against theoretical expectations, published research suggests that differentials in responsiveness are weaker in the United States compared to other developed democracies. The article contributes to our understanding of differential responsiveness by clarifying the main debates and findings in the literature, identifying issues and gaps, and pointing to fruitful avenues for future research.
\end{abstract}

$\square$ ising inequality has led to an emerging literature that investigates how equally political outcomes respond to the preferences of individuals in different income groups (APSA 2004). Influential studies of the United States find a clear income bias in political responsiveness. Gilens (2012, 1), for instance, argues that "responsiveness is strongly tilted toward the most affluent

Data replication sets are available in Harvard Dataverse at https://doi.org/10.7910/DVN/4ECXDG

Mads Andreas Elkjer (1) is a postdoctoral research fellow in the Department of Politics and International Relations at the University of Oxford and Nuffield College (mads.elkjaer@ politics.ox.ac.uk). His research interests include political representation, inequality, redistribution, and, more broadly, comparative politics and political economy. His work has appeared in World Politics, Comparative Political Studies, and West European Politics.

\footnotetext{
Michael Baggesen Klitgaard (1) is a professor of political science and head of the Department of Politics and Society at AalborgUniversity (michaelklitgaard@dps.aau.dk). His research interests include business and elite influence on democracy, tax policy, interest groups, and party politics. His work has appeared in outlets such as the American Journal of Political Science, European Journal of Political Research, Journal of European Public Policy, and West European Politics.
}

citizens" (see also Bartels 2008; Gilens and Page 2014). Comparative scholars, extending the US-based analyses to European democracies, echo this conclusion (Elsässer, Hense, and Schäfer 2018; Schakel 2019).

These findings have vast theoretical and normative implications, challenging literatures on democratic policy making and political representation and contradicting the democratic virtue of political equality. Perhaps not surprisingly then, the findings have attracted not only considerable academic attention but also considerable public attention. Following the publication of Gilens and Page (2014), news media asked whether the United States should be classified as an oligarchy rather than a democracy-a question the authors received the opportunity to discuss with Jon Stewart on the comedic TV news show, The Daily Show. ${ }^{1}$ And in 2008, Larry Bartels's book Unequal Democracy was referenced by then-presidential candidate Barack Obama (Enns 2015, 1053), a fact so well known that it recently was made into a question on the TV show Jeopardy. ${ }^{2}$ By now, it has become a stylized fact that "rich people rule!"3

Yet while these influential studies point to a strong income bias in political representation, important nuances come to light when considering the literature as a whole. Often, the preferences of income groups overlap in a way that yields roughly equal representation, and even when income groups have opposing preferences, representational disparities are limited and better explained by partisanship than affluence (Branham, Soroka, and Wlezien 2017; Brunner, Ross, and Washington 2013; Enns 2015; Lax, Phillips, 
and Zelizer 2019; Soroka and Wlezien 2008). More recent work suggests that the standard methodological setup used in the literature is biased toward the preferences of the rich and finds middle-class dominance using an alternative, comparative framework (Elkjær and Iversen 2020). Thus, the degree and extent of unequal democracy, as well as what may be driving it, remain disputed.

In the latest (narrative) review of the literature, Erikson $(2015,27)$ suggested that representational disparities may be driven by lower levels of political participation and information among the poor and encouraged future research to "continue to focus on whether politicians actually ignore the preferences of less affluent voters, and if so, why." Empirical research has continued along these lines since then, resulting in a doubling of the number of published studies and the emergence of a comparative literature. But despite the important democratic and theoretical implications of the literature and the massive scholarly and public attention, we still have no systematic account of the severity of differentials in political responsiveness or the potential drivers. In addition, how the comparative findings compare to those from the United States has yet to be systematically assessed.

Because the debates in this literature are so important for our understanding of democracy, it is critical to have a nuanced understanding of what the literature actually tells us. Given its recent development-with studies raising questions about the validity of the original conclusions and the emergence of a comparative literature-we believe the time is ripe for taking a systematic look at published research to help advance informed scholarly and public debates.

In this article, we present the first systematic review of the literature on differential political responsiveness with the aim of synthesizing our collective knowledge of (1) the degree of differentials in political responsiveness, (2) their potential drivers, and (3) the variation across democracies. First, we provide a narrative overview of these debates. We then use a new dataset that contains 1,163 estimates of political responsiveness by income group from 25 studies to analyze the key findings of published research. We find that, although the literature collectively points to a positive income gradient in political responsiveness, there is considerable divergence in results across models and studies. This divergence is partly explained by partisanship, but more importantly by the model specification: differentials in responsiveness are much starker when assessed in a statistical model that includes the preferences of several income groups, rather than using separate models for each income group. There is no significant variation in results across either policy domains or general/specific measures of political outcomes. Finally, we show that contrary to conjectures that strong differentials in responsiveness may be unique to the US political system, comparative studies actually observe starker differentials than those found in the United States. After presenting these results, we discuss their implications for our understanding of political responsiveness and for future research, emphasizing that published research points to the presence of a generic driver that affects responsiveness similarly across contexts.

\section{A Narrative Review of Three Key Debates}

This section provides a narrative review of three key debates related to the degree of differential political responsiveness, the potential drivers of published results, and the extent of differential responsiveness across democracies.

\section{The Degree: How (Un)Equal Is Political Responsiveness?}

The overarching research question in the literature can be phrased as follows: How equally do political outcomes respond to the preferences of individuals in different income classes?

Bartels (2008) and Gilens (2005, 2012) were among the first to empirically probe the question. Bartels (2008) studies the roll-call voting of US senators in the $101 \mathrm{st}$, 102nd, and 103rd Congresses and finds that senators respond most strongly to the preferences of the affluent, to a lesser extent to those of the middle class, and not at all to those of the poor. As opposed to studying roll-call voting and general ideology, Gilens $(2005,2012)$ examines the association between support for changes in specific policies and whether these policies changed in subsequent years. Across all policies, Gilens finds just a slight income gradient in political responsiveness, but when preferences differ by more than a few percentage points, changes in policies reflect only the preferences of the affluent.

Since the publication of these influential studies, scholars have extended and tested Bartels's approach in other time periods with mixed results (Bhatti and Erikson 2011; Flavin 2012a; Hayes 2012; Tausanovitch 2016). Gilens's approach has been extended to tests of major theories of democracy and differential responsiveness in Germany and the Netherlands with very similar results (Elsässer, Hense, and Schäfer 2018; Gilens and Page 2014; Schakel 2019). Studies examining variation in political outcomes across US states and affluent democracies have also been added to the literature (Bartels 2017; Flavin 2012b; Peters and Ensink 2015; Rigby and Wright 2011; 2013; Schakel, Burgoon, and Hakhverdian 2020). The general impression is that the preferences of the rich receive more consideration in the policy-making process than those of the lower and middle classes - and often a lot more.

These findings, however, have not gone unchallenged. An important critique, which comes in two separate forms, is that income groups often have similar and highly correlated preferences. The first form emphasizes that the high degree of similarity of preferences creates a natural limit to unequal representation: even if the rich drive 
public policies, the preferences of lower-income groups will still be represented, albeit coincidentally (Soroka and Wlezien 2008; but see Gilens 2009). Enns (2015) argues that, even when preferences differ, considerable "coincidental representation" of lower-income groups can occur because all groups tend to rank policies similarly in terms of popularity. Several studies that use bivariate models to show that political outcomes align about equally with the preferences of all income groups provide evidence in favor of this argument (Soroka and Wlezien 2010; Ura and Ellis 2008; see also Wlezien and Soroka 2011).

Yet not everyone is equally optimistic about the implications of these results: some scholars argue that we should care more about the relative influence of different groups than on how well political outcomes align with group preferences. For instance, Gilens (2015b, 1070) argues that coincidental representation is a "pale, counterfeit, simulacrum of democracy" that cannot take the place of real democratic responsiveness, and Bartels $(2017,23)$ would still attach "considerable theoretical and moral significance to the class bias," even if all groups receive the policies they prefer (see also Gilens and Page 2014). Thus, even though there tends to be little difference in how well political outcomes align with the preferences of income groups, the democratic implications of this result remain contested.

The second form of the critique is methodological and highlights how the high level of collinearity of preferences can complicate statistical analyses. Bhatti and Erikson (2011) — besides correcting a weighing issue — cannot replicate the findings of Bartels (2008) on new data due to high levels of multicollinearity. And in an extension of Gilens and Page (2014), Bashir (2015) uses simulations to argue that the middle class may actually be as influential as the affluent, but that statistical models have difficulties separating the influence of the two groups because their preferences are highly correlated (but see the response by Gilens [2016] who argues that Bashir's critique is misplaced).

Stimson (2011) further points out that because higherincome individuals tend to be better informed about politics the preferences of high-income groups are likely to be estimated with less measurement error than those of low-income groups. In combination with high levels of multicollinearity in multivariate models, such differential measurement error can generate the finding that only the preferences of the rich matter-because the group whose preferences are estimated with least error will dominate the regression-even if political responsiveness were in fact equal (for technical treatments of how multicollinearity can compound model misspecification and measurement error bias, see Winship and Western [2016] and Kalnins [2018]).

To circumvent these issues, Branham, Soroka, and Wlezien (2017) adopt a different approach, examining who wins when groups disagree instead of political responsiveness. Using the data from Gilens (2012), they show that it is rare that one income group favors a policy change while another income group opposes it. This happens in only about 1 of 10 cases when comparing the affluent to the middle class, and because survey companies mainly ask about contentious issues, even this low number probably overstates the degree of disagreement between income groups on the full sample of policies. Disregarding potential issues of sample selection, Branham, Soroka, and Wlezien (2017) find that on the small subset of policies on which middle and high-income groups have opposing preferences, the rich get their way just marginally more often than the middle class $(53 \%$ vs. $47 \%)$.

Building on this insight, Lax, Phillips, and Zelizer (2019) use several different measures of political representation-responsiveness, congruence, and a "takingsides approach" - to examine the roll-call voting of US senators. Their findings indicate that senators respond more strongly to the preferences of the rich than to those of the poor, but the authors note that the responsiveness regressions are "messy to interpret" and that "given problems of multicollinearity, we need to be careful not to place too much faith in these regressions" (928). Indeed, when using alternative measures of representation, these authors find considerably smaller disparities in representation. All in all, recent studies raise questions about the validity of the original conclusions, suggesting that parts of the literature overestimate inequalities in political responsiveness.

The debates about model estimation and whether it is differences in relative influence or in the alignment between political outcomes and preferences that matter suggest that the divergence of published results may partly reflect differences in the model specification; specifically, whether inequalities in political responsiveness are assessed using one model for each income group or one model for all groups. But although it seems fairly well established that the latter approach tends to produce greater differentials than the former, we have no estimates of how dependent the results are, and we are far from reaching a general agreement on the implications: Does the model dependence reflect statistical issues or theoretically meaningful differences in results? To help increase clarity about the divergence of published results and contribute to a better understanding of the model dependence, we examine the consequences of different model specifications in the quantitative part of the review.

\section{Potential Drivers}

Does Partisanship Condition Who Is Represented? Standard theories of democracy predict that left-leaning parties respond to the preferences of lower-income individuals and right-leaning parties to those of higher-income 
individuals. Because the middle class occupies a favorable position in the middle, it is seen as decisive for who is elected for office, and its preferences should almost always be represented. Accordingly, policies would reflect the preferences of the majority (those of the middle plus those of either the lower or upper class), and differentials in responsiveness would depend solely on who is in office. By contrast, if some groups were systematically overrepresented regardless of who is in office, it would be a distortion of the democratic principle of "one person, one vote." Because the democratic implications of differential responsiveness depend (at least in part) on the patterns observed under different types of governments, partisanship is an important potential driver of differential responsiveness that has been closely scrutinized in the literature.

In the US Senate, Bartels (2008) finds patterns partly consistent with both the partisan and distorted view of democracy: partisanship does matter, because Democrats attach relatively more weight to middle-class preferences than do Republicans, but both parties respond most strongly to the preferences of the affluent and completely ignore those of the poor. In the House of Representatives, Rhodes and Schaffner (2017) find patterns most consistent with partisan democracy: Republicans respond to the preferences of the rich and Democrats to those of the poor.

Lax, Phillips, and Zelizer (2019) provide an important qualification to these results. They show that, although it is descriptively true that Republicans vote with the rich and Democrats with the poor, this is because the two parties respond to the preferences of their co-partisans and Republicans, on average, are more affluent than Democrats (see also Brunner, Ross, and Washington 2013). Maks-Solomon and Rigby (2020), however, find that both parties respond more strongly to their rich co-partisans, suggesting that although partisanship matters more than income, US senators may have incentives to cater to the preferences of their more affluent voters.

Although these results are, at least partly, consistent with partisan democracy and the received wisdom that Democrats represent lower-income classes better than Republicans, other studies reach more ambiguous conclusions. Gilens (2012) finds that both parties overrepresent the affluent on most issues and that Republicans overall are more responsive to public opinion. Across US states, Rigby and Wright (2013) find that whereas Republican state party platforms respond roughly equally to middleand high-income preferences, Democratic platforms respond most strongly to the preferences of high-income groups, especially in states with high levels of inequality. Within state parties, Republicans appear most responsive to their rich co-partisans on economic issues and their middle-class voters on social issues. Democrats, by contrast, appear more responsive to their rich co-partisans on both economic and (especially) social issues (Wright and
Rigby 2020). These findings suggest that in some cases Republicans may actually produce less representational inequality than Democrats (see also Hayes 2012).

Overall, then, the US literature presents somewhat contradictory evidence about whether and how partisanship matters for political responsiveness. We next combine the findings of published responsiveness studies to examine the effects of partisanship in more detail. ${ }^{4}$

Heterogeneity in Results across Policy Domains or Levels of Aggregation? Examining variation in results across policy domains and political outcomes may help us understand the underlying mechanisms of differential responsiveness.

Bartels (2008) and Gilens (2012) consider several potential mechanisms of their findings and appear to agree that their results are most consistent with the role of money in politics. The view that money in politics undermines equal representation follows from what some perceive as a clash between democracy and capitalism, according to which the unequal distributions of income and wealth generated by capitalism distort political equality.

If unfettered crony capitalism creates incentives for the rich to invest in politics to further distort market outcomes, thereby creating a vicious cycle between economic inequality and political inequality, we would expect to observe the starkest differentials in responsiveness on economic domains, because economic policies directly affect the distribution of income and wealth. Economic policies are also what the rich care about the most (Page, Bartels, and Seawright 2013).

Similarly, if money in politics is an important driver of published findings, we should expect to observe starker differentials on more specific policies. This is because visibility is lower on more specific, technical policies, which gives the rich and organized interests more leeway to exert political influence (Hacker and Pierson 2010).

In contrast to the implications of money in politics, we should see no systematic variation in results across domains or outcomes if the differentials are driven by something generic. For example, if the differentials are caused by politicians responding to voters (as opposed to citizens) or if lower levels of information cause more measurement error in estimates of low-income preferences (as suggested by Erikson 2015 and Stimson 2011), there should be little to no variation across domains and outcomes.

To help us understand the underlying mechanisms of unequal representation, we examine the variation of published results across policy domains and political outcomes below.

\section{The Extent: American Exceptionalism or Worldwide Unequal Representation?}

Because the United States is unique among advanced democracies in terms of the degree of economic inequality 
and its system of private campaign financing, we would expect to observe weaker differentials in political responsiveness in other developed democracies. Yet Peters and Ensink (2015) and Bartels (2017) find in broader sets of affluent, mainly European, democracies that the rich exert an outsized influence on social spending to the extent that spending (often) moves against the preferences of the poor. Schakel, Burgoon, and Hakhverdian (2020) corroborate these results, arguing that rich people decide the generosity of welfare policies in advanced democracies.

In general, there is little evidence that differentials in responsiveness vary across political-economic contexts (Bartels 2017). Peters and Ensink (2015) do argue that lower turnout rates beget more representational inequality, but their results suggest that responsiveness is unequal only when the turnout rate is below $40 \%$, which is lower than any country in their sample experienced during the study. The main contribution of these cross-national studies, therefore, is to document differentials in responsiveness outside the United States; they provide less information about the potential drivers.

A similar conclusion holds for single-country studies. Studying referenda voting in Switzerland, Stadelmann, Portmann, and Eichenberger (2015) find that only the rich appear to exert independent influence. In Germany and the Netherlands, Elsässer, Hense, and Schäfer (2018) and Schakel (2019) closely reproduce the results of Gilens (2005) and suggest that their results may be driven by disparities in political participation, descriptive representation, or interest-group mobilization; yet only Schakel (2019) conducts empirical tests but finds inconclusive evidence.

Considering the pronounced economic, political, and institutional differences between the United States and Europe, the similarity of the comparative and US findings is puzzling. How can we account for it?

Elkjær and Iversen (2020) question whether findings of differential responsiveness reflect inequalities in substantive political representation. Using simulations, they show that if political information differs across groups one can get biased results when studying preferences for change and changes in policies, which is what most studies examine. Even if the middle class is politically pivotal and decides the long-run level of a policy, statistical models can produce the result that only the preferences of the rich matter, if the rich are better informed than the lower and middle classes. ${ }^{5}$ To avoid bias, they propose studying longrun levels of policies instead of short-term changes.

Empirically, Elkjær and Iversen (2020) test their argument using data on preferences for redistribution and social spending from 21 advanced democracies. The results are corroborative, showing that short-term changes in spending, during a period in which spending increased significantly, appear to have been driven by the preferences of the rich, but the preferences of the middle class seem to have decided the long-run levels. Using Danish data, Elkjær (2020) finds further corroborative evidence: the pattern of differential responsiveness observed in Denmark is remarkably similar to those observed in the United States and elsewhere in Europe but appears to be driven by better information among affluent Danes, who express preferences that are more in line with standard macroeconomic policies. ${ }^{6}$ These results suggest that differentials in political responsiveness may (partly) reflect differences in information across groups, rather than inequalities in substantive political representation.

In sum, comparative studies have investigated the extent of differential responsiveness across democracies, explored differences in results across contexts, and, most recently, questioned the interpretation of the main finding of the literature. The comparative branch of the literature can help place the US findings in a broader context by providing benchmarks from other countries and, to the extent that there is inequality in responsiveness, by highlighting some of the potential drivers. Below we provide a systematic, quantitative analysis of similarities and differences in results across contexts.

\section{Quantitative Analysis}

\section{Study Eligibility Criteria}

We focus the quantitative review on English-language journal articles, books, book chapters, and working papers from working paper series published between 2004 and $2020 .^{7}$ To be eligible for inclusion in the quantitative review, a study from this universe of studies must satisfy two criteria. First, its main text must present the results from at least one statistical model that analyzes political responsiveness following the definition of Achen (1978). Consequently, political responsiveness must be measured as the slope coefficient on preferences in a regression that regresses some political outcome on related political preferences. ${ }^{8}$ The political outcome can be either a specific policy (as in Gilens 2012) or some aggregate measure (such as NOMINATE-scores, as in Bartels 2008). Second, the study must explicitly compare the responsiveness of political outcomes to the preferences of at least two income groups. This can be done using either bivariate or multivariate models.

Focusing on political responsiveness has the consequence of excluding a branch of literature that examines disparities in ideological and policy congruence (e.g., Ellis 2013). Studies of congruence have similar objectives as those of responsiveness, but the estimation strategies differ in important ways, which complicates direct comparisons (see Achen 1978; Wlezien 2017). We focus on political responsiveness because that is what the most influential studies investigate (Bartels 2008; Gilens 2005, 2012; Gilens and Page 2014). Needless to say, our focus is not an indication that studies of congruence are unimportant 
parts of the literature but that systematically reviewing those studies is better left for future research.

\section{Search Strategy and Study Selection}

To ensure a systematic and transparent process of selecting studies, we adhered to a widely used set of recommendations developed for systematic reviews in the medical sciences (Liberati et al. 2009). Figure 1 illustrates our study selection procedure. Using search strings such as "unequal representation" and "differential responsiveness," we conducted topic searches on Web of Science and Google Scholar to identify potentially relevant studies. Our literature search yielded a total of 1,561 potentially relevant studies, which we screened on the title, abstract, language, and publication status. This reduced the set of potentially relevant studies to 85 . Based on full-text assessments of the 85 studies, 24 studies qualified for inclusion in the quantitative review. To minimize the risk of omitting a relevant study, we assessed the references of all eligible studies, which yielded one additional study. Last, we discussed our list of studies with experts in the field, but this did not lead to new studies. We therefore ended up with 25 studies in total.

Having identified the studies, we recorded all estimates of political responsiveness from additive models, and from interactive models if the exact conditional effect was reported, together with the associated standard errors. We also recorded basic information about the study, such as the country, preferences, political output being analyzed, and how respondents were divided into income groups. Detailed information on the literature search and the included studies is provided in online appendix A.

\section{Main Results of Studies of Differential Political Responsiveness}

Figure 2 summarizes the main results of published studies that statistically assess the link between affluence and political responsiveness. The $y$-axes show the regression coefficients, where higher values mean greater political responsiveness, and the $\mathrm{x}$-axes denote the location of an income group in the income distribution from the survey. ${ }^{\text {? }}$ The gray dots are the coefficients reported by a study, and the black lines are LOESS smoothers that describe the overall association between income and political responsiveness for each study.

The figure shows that most studies find a positive income gradient in political responsiveness, indicating that political outcomes respond more strongly to the preferences of higher-income groups (e.g., Bartels 2008; Gilens 2005). At the same time, it illustrates a considerable divergence in results. Some studies find relatively equal levels of political responsiveness (Soroka and Wlezien 2010;

\section{Figure 1}

\section{Flow Diagram of Study Selection}

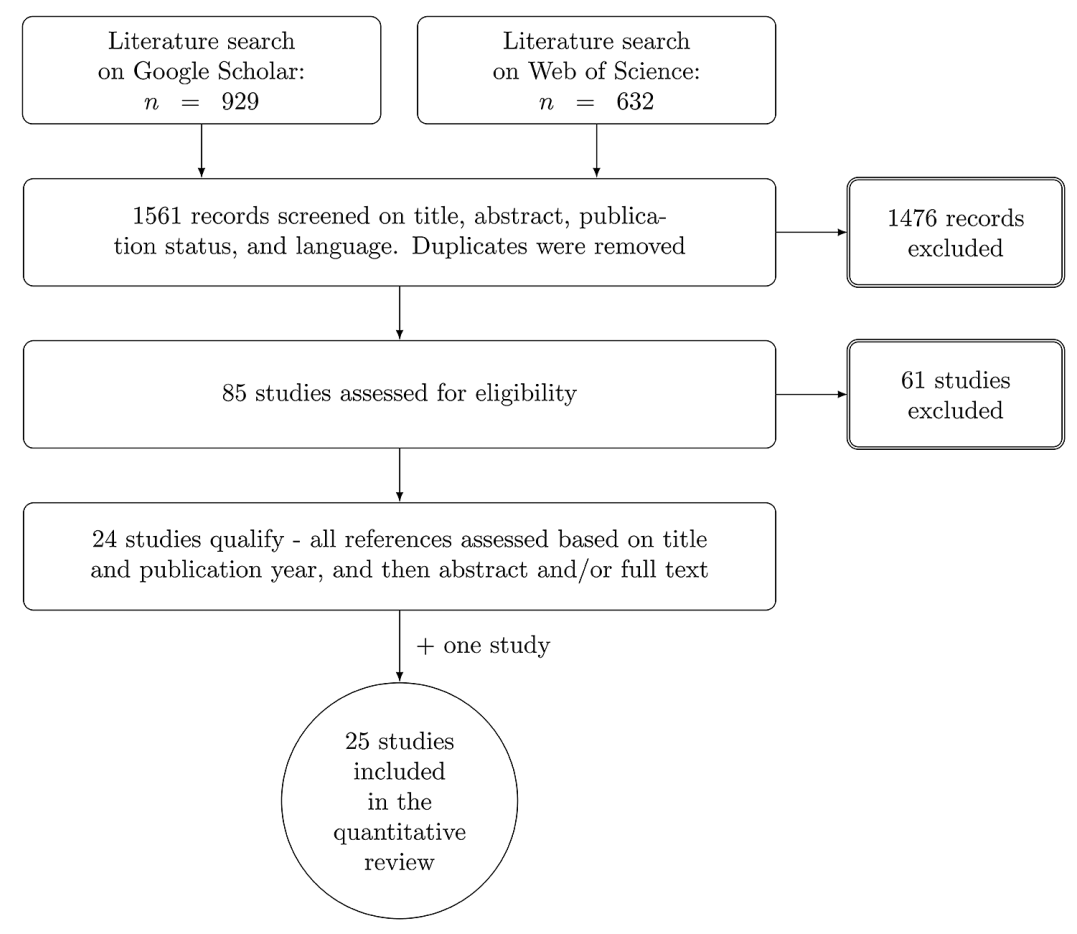




\section{Figure 2}

\section{Main Results of 26 Studies of Differential Political Responsiveness}

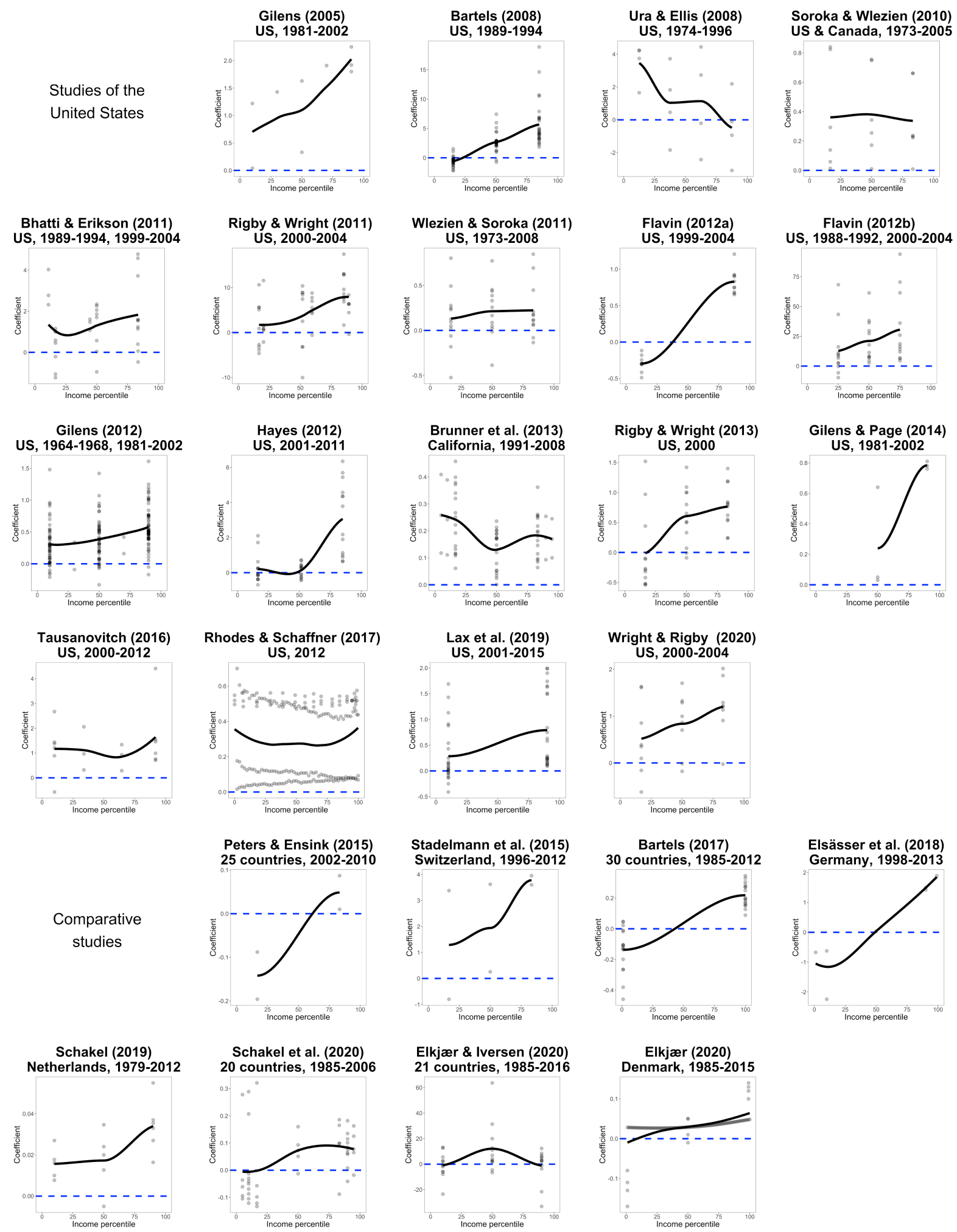

Note: The studies are ordered by region and publication date. Because Gilens (2005) presents similar results as Gilens (2012), the study is not included in the later statistical analyses, but we include it here to illustrate the development of the literature. $N=1,172$. Without Gilens (2005), $N=1,163$. 


\section{Figure 3}

Test Statistics of Low, Middle, and High-Income Coefficients

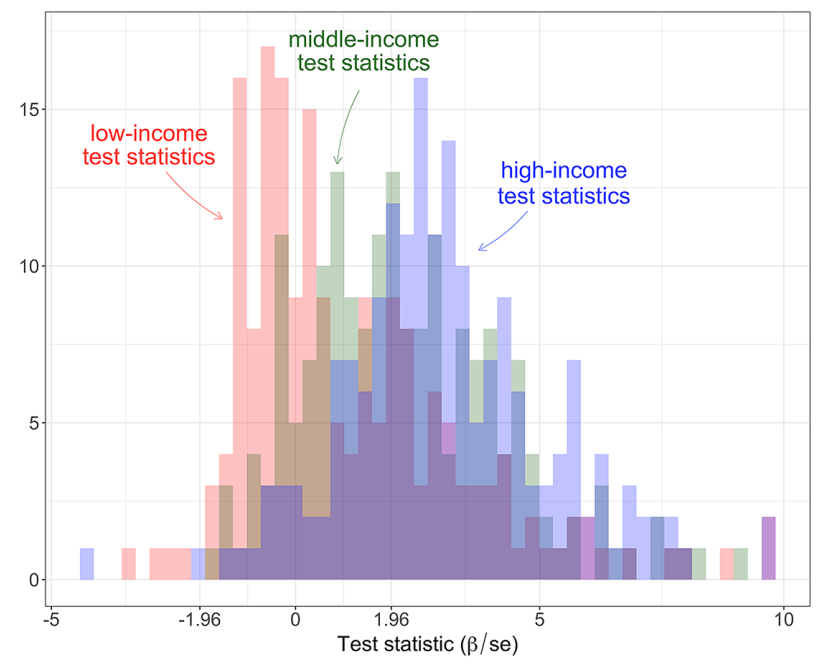

Note: The figure shows the distribution of test statistics of the low(red), middle- (green), and high-income coefficients (blue) displayed in figure 2. If a study reports the coefficients of more than three income groups, the figure shows the test statistics of the groups with the lowest, median, and highest income. The $x$-axis is truncated at 10 because a few coefficients have very large test statistics. $\mathrm{N}=829$.

Tausanovitch 2016; Wlezien and Soroka 2011), some find that political outcomes best reflect the preferences of the poor (Brunner, Ross, and Washington 2013; Ura and Ellis 2008), and still others find that political outcomes respond most strongly to the preferences of the middle class (Elkjær and Iversen 2020). This divergence in results is often downplayed in scholarly and public discussions of the literature, yet it stands out clearly here.

Another striking feature of figure 2 is the similarity of findings across the US and comparative studies. One may be tempted to interpret this similarity as an indication that some degree of political inequality is inherent in capitalist democracies, but considering the widely different political-economic contexts of the United States and Europe, we would still expect to observe cross-national variation. It is, for instance, hard to see how political responsiveness can be equally unequal in countries like Germany or Denmark compared to the United States given these European countries' much more equal distributions of income, stronger labor unions, higher turnout rates, and a smaller role of money in politics. From a theoretical point of view, the similarity of results across political-economic contexts is puzzling.

In figure 3, we display the test statistics of the coefficients shown in figure 2. Figure 3 shows that high-income coefficients more often have positive and larger test statistics than do lower-income coefficients. The median test statistic of high-income coefficients is 2.95 , whereas it is 2.0 and 0.3 for middle and low-income coefficients, respectively. For all groups, the figure shows a small uptick in coefficients with test statistics around the typical significance threshold of 1.96, which suggests the presence of some publication bias in the literature. The most striking features of figure 3 , however, are that only about one of three low-income coefficients are positive with test statistics above 1.96 and that $43 \%$ are negative. In contrast, every other middle-income coefficient and three of four high-income coefficients are positive with test statistics above 1.96 , and only $14 \%$ and $5 \%$ of middle and highincome coefficients, respectively, are negatively signed. Figure 3 thereby complements figure 2, suggesting that the poor especially lack a strong, consistent political voice. Neither figure, however, provides much direct evidence about the degree of differential responsiveness, a question we turn to now.

\section{The Degree of Differential Political Responsiveness}

To assess the degree of differentials in political responsiveness, it is necessary to compare coefficients across studies and models within studies. But because studies rely on different measures of political preferences and outcomes, it is not possible to do so directly. One way to ensure comparability would be to calculate standardized effects, but Achen (1977) warned us of the pitfalls of this approach decades ago; even if we wanted to adopt this approach, it is complicated by the fact that studies rarely report the statistics needed for standardization. Another option would be to calculate ratios of income-group coefficients, but that is also not feasible because of the many negative low-income coefficients.

Instead, we create two ordered categorical variables that compare high-income coefficients to low- or middleincome coefficients. ${ }^{10}$ The middle category on the two variables has the value 4 and describes cases of relatively equal representation in which the sizes of two coefficients are within $15 \%$ of one another. Categories 3 and 5 describe a moderate bias in political responsiveness favoring either the poor/middle class or the rich in which one coefficient is equal to or more than $15 \%$ the size of the other but less than twice as large. Categories 2 and 6 contain cases of more severe bias in which one coefficient is equal to or more than twice as large as the other. Categories 1 and 7 describe the most extreme form of biased responsiveness in which political outcomes reflect the preferences of one group (implying a positive coefficient) while going against those of the other (implying a negative coefficient). Last, an auxiliary category contains ambiguous results in which both coefficients are either negative or statistically insignificant at the 0.1 level, suggesting nonresponsiveness of the political outcome to the preferences of both groups. ${ }^{11}$ 


\section{Figure 4 \\ Differentials in Political Responsiveness Are More Pronounced between High and Low-Income Groups (A) than between High and Middle-Income Groups (B)}
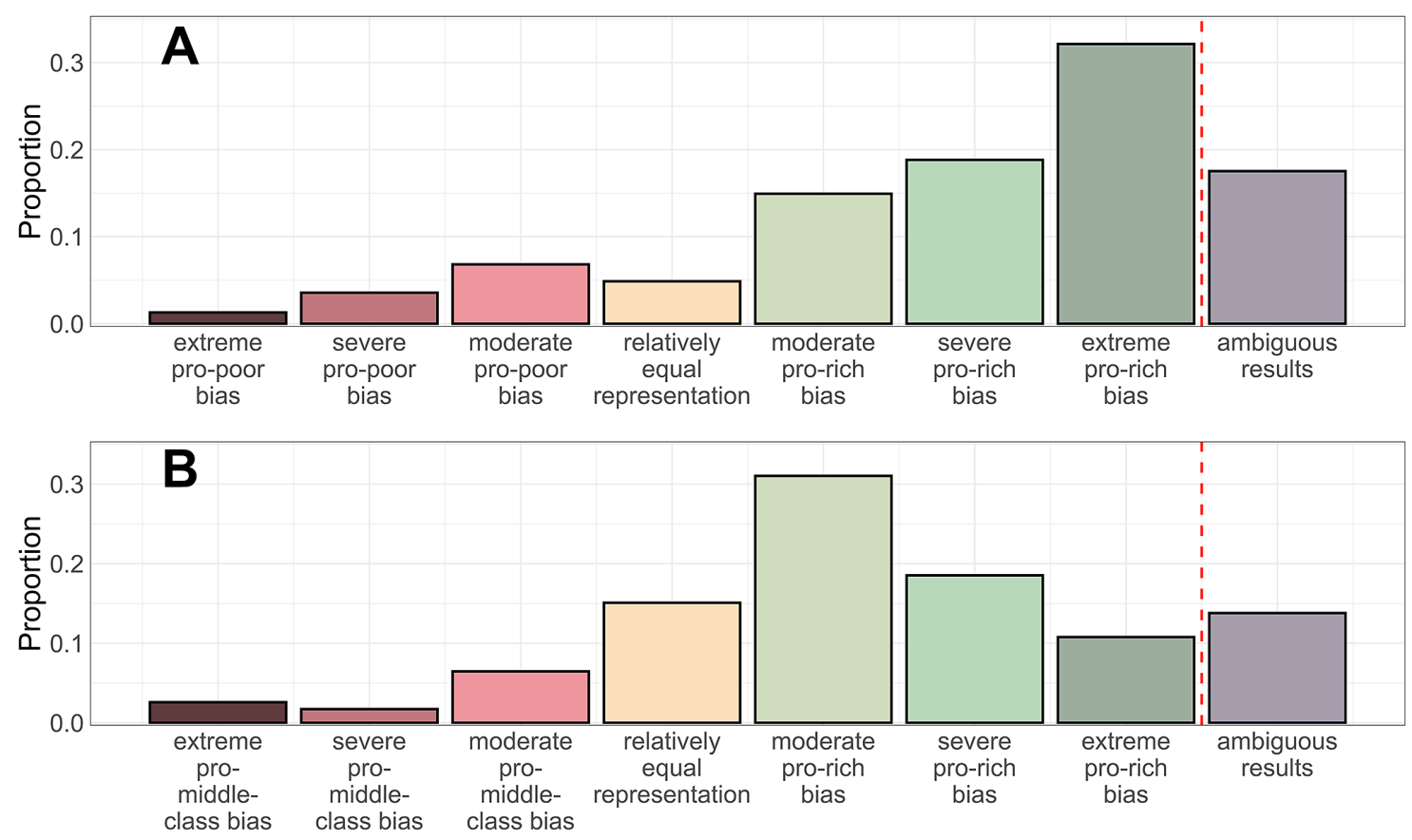

Note: The figure shows the distributions of two categorical variables that compare the political responsiveness of high-income groups to those of low- (panel A) and middle-income groups (panel B).

$\mathrm{N}_{A}=308 . \mathrm{N}_{B}=232$.

The advantage of this coding is that it allows us to examine all cases of differential responsiveness in one model while still capturing degrees of intensity. It also limits the influence of extreme observations. The drawback is that it forces us to choose arbitrary cutoff points. To ensure that the choice of cutoff points is not driving the results of the quantitative review, we experiment with different values in online appendix B. In all cases, the results are similar to those presented here.

Figure 4 displays the distributions of the two variables. The high-low income comparison in panel A shows that published research collectively suggests that the preferences of the rich are vastly better represented than those of the poor. Whereas the preferences of the rich appear better represented in two of three cases (the green-shaded bars), those of the poor appear better represented in just $12 \%$ of cases (the red-shaded bars). In a mere $5 \%$ of cases, the representation of the two groups is roughly equal (the yellow bar). Ambiguous results account for the remaining $18 \%$ (the purple bar). Figure $4 \mathrm{~A}$ also shows that the most extreme pro-rich bias-where the coefficient of the highincome group is positive, whereas that of the low-income group is negative-is the most frequent finding of the literature (32\% of comparisons). This finding is striking because it suggests not only that the affluent are better represented than the poor but also that political outcomes often appear to be directly opposed to the preferences of the poor. At the same time, the finding is puzzling, because one of the most consistent findings in the literature is that the preferences of income groups are highly correlated. How political outcomes, in such a context, can be positively associated with the preferences of the rich while simultaneously be negatively associated with those of the poor warrants further scrutiny; we dig deeper in the next section.

Figure $4 \mathrm{~B}$ shows that, compared to high- and lowincome groups, differentials in political responsiveness between high- and middle-income groups are both less commonly observed and less severe. About $60 \%$ of empirical models find that high-income preferences are better represented than middle-income preferences, most often with a factor less than two (the moderate pro-rich bias with $31 \%$ ), whereas about $10 \%$ find that the middle class is better represented than the rich. Representation is roughly equal between high and middle-income groups in $15 \%$ of cases; ambiguous results characterize the last $14 \%$.

A final noteworthy feature of figure 4 is that the literature includes considerably more high-low than high-middle income comparisons (see the note to the figure), which considering the omnipresence of median-voter models in 
literatures on democratic policy making and political representation seems peculiar. Directing attention to middleincome individuals should be an obvious next step for the literature; this is especially so for the comparative literature, which reports more than twice as many high-low as highmiddle income comparisons.

\section{The Extent and Drivers of Differential Political Responsiveness}

We now turn to the analysis of the extent and drivers of differential responsiveness, examining how published results vary across regions, model specifications, partisanship, issue specificity, and policy domains. To account for the hierarchical structure of the data and the ordered categorical nature of the dependent variables (shown in figure 4), we estimate random-effects ordered logistic regressions with models nested within studies. ${ }^{12}$ As controls, we include a measure of the distance in the income distribution between the income groups and the number of observations used to estimate the model. We also include a dummy for whether the model is estimated on a subset of policies on which preferences diverge. ${ }^{13}$

Table 1 presents the results. ${ }^{14}$ Models (1) and (2) show the results for the high-low income comparison on a full sample of all studies and on a subsample of US studies, respectively. Likewise, models (3) and (4) display the results for the high-middle income comparison. ${ }^{15}$ Because the logit coefficients in the table are difficult to interpret substantively, we analyze more meaningful predicted probabilities later. For now, we want to highlight that the results are unaffected by the inclusion of the comparative studies, which demonstrates the high comparability of results across contexts. We also note that the relative distance in the income distribution between high- and low/middle-income groups is unrelated to differentials in responsiveness, suggesting that how scholars define income groups has little bearing on the results. And as discussed, Gilens (2012) — and the studies extending this approach to other contexts-find greater differentials in responsiveness when preferences diverge.

In models (5) and (6), we analyze why published results sometimes are ambiguous. The models show that a larger sample size is associated with a lower likelihood of obtaining ambiguous results, reflecting the greater statistical power of the estimated model. Results are also less likely to be ambiguous when studying general ideology, rather than specific policies, which comports with the findings of the broader literature on political responsiveness (Erikson 2015, 12-13). Finally, including more than one set of preferences in the model specification increases the probability of obtaining ambiguous results for the high-low income comparison (from .12 to .21), which is probably due to higher levels of multicollinearity as explained by Bhatti and Erikson (2011).

\section{How Do Differentials in Responsiveness Vary across Model and Study Characteristics?}

To present more intuitive estimates of how differentials in responsiveness vary across model and study characteristics, we use in-sample predictions to calculate the probability of obtaining a certain degree of differential responsiveness for each characteristic. These probabilities can be interpreted as the predicted proportion of published findings that fall into the different categories of differential responsiveness, given the model specified in table 1 . We rely on the pooled samples of all studies for every predictor except partisanship, for which we use the US-specific sample (because only US studies disaggregate the analysis by party).

Number of Groups Included in a Model. Whether a statistical model includes the preferences of one or more income groups turns out to be a strong predictor of the most extreme form of differential responsiveness, where the coefficient of the rich is positive (and significant) and that of the lower-income group is negative. Figure 5 shows that, whereas the probability of observing such extreme differentials in responsiveness between high- and lowincome groups is .08 for models that include preferences separately, the probability is .59 for models that include preferences simultaneously. In fact, findings of extreme pro-rich bias are almost entirely driven by this one modeling choice. Wholly $96 \%$ of the statistical models that have produced this result thus include the preferences of multiple income groups simultaneously in one model. For the high-middle income comparison, the probabilities of observing an extreme pro-rich bias are .09 and .15 , and $84 \%$ of the statistical models that have produced this finding include multiple sets of preferences. Not only does the multivariate model estimate starker differentials in responsiveness but it is also more likely to find an overrepresentation of the rich. The probability that the rich appear better represented than the poor (middle class) increases from .68 to $.88(.61-.82)$ when including the preferences of more than one income group in one statistical model (the green shades combined).

The model dependency of published research relates to one of the biggest discussions in the literature about the effects of highly correlated preferences. But because, as discussed in the narrative review, scholars disagree on whether the model dependence reflects statistical issues or substantively meaningful differences in results across specifications, it remains highly contested which model better captures actual differences in democratic responsiveness.

To help move the debate forward, let us consider the two possible scenarios. The first scenario is one in which the multivariate model captures inequalities in political influence, whereas the bivariate model captures the unconditional alignment between political outcomes and preferences 
Table 1

Predictors of Differential Political Responsiveness in Published Research

\begin{tabular}{|c|c|c|c|c|c|c|}
\hline & \multicolumn{2}{|c|}{ High vs. Low } & \multicolumn{2}{|c|}{ High vs. Middle } & \multicolumn{2}{|c|}{ Ambiguous Cases } \\
\hline & All & US & All & US & H-L & H-M \\
\hline & (1) & (2) & (3) & (4) & (5) & (6) \\
\hline \multicolumn{7}{|l|}{ Study/Model Characteristics } \\
\hline $\mathrm{N}$ of groups $>1$ & $\begin{array}{l}3.62^{*} \\
(0.51)\end{array}$ & $\begin{array}{l}3.24^{\star} \\
(0.54)\end{array}$ & $\begin{array}{c}1.69^{\star} \\
(0.38)\end{array}$ & $\begin{array}{l}1.74^{*} \\
(0.46)\end{array}$ & $\begin{array}{l}1.14^{\star} \\
(0.51)\end{array}$ & $\begin{array}{c}0.63 \\
(0.61)\end{array}$ \\
\hline Partisanship: Democrat & & $\begin{array}{l}-0.78 \\
(0.46)\end{array}$ & & $\begin{array}{c}0.21 \\
(0.43)\end{array}$ & $\begin{array}{c}0.64 \\
(0.59)\end{array}$ & $\begin{array}{c}1.02 \\
(0.77)\end{array}$ \\
\hline Partisanship: Republican & & $\begin{array}{c}0.84 \\
(0.43)\end{array}$ & & $\begin{array}{l}-0.22 \\
(0.39)\end{array}$ & $\begin{array}{c}0.87 \\
(0.54)\end{array}$ & $\begin{array}{l}-0.06 \\
(0.80)\end{array}$ \\
\hline Domain: Non-economic & $\begin{array}{l}-0.23 \\
(0.56)\end{array}$ & $\begin{array}{l}-0.01 \\
(0.60)\end{array}$ & $\begin{array}{l}-0.05 \\
(0.42)\end{array}$ & $\begin{array}{c}0.01 \\
(0.46)\end{array}$ & $\begin{array}{l}-0.09 \\
(0.64)\end{array}$ & $\begin{array}{l}-0.99 \\
(0.73)\end{array}$ \\
\hline Domain: Economic & $\begin{array}{c}0.50 \\
(0.67)\end{array}$ & $\begin{array}{c}0.61 \\
(0.73)\end{array}$ & $\begin{array}{l}-0.67 \\
(0.51)\end{array}$ & $\begin{array}{l}-0.41 \\
(0.61)\end{array}$ & $\begin{array}{c}0.33 \\
(0.68)\end{array}$ & $\begin{array}{l}-0.72 \\
(0.82)\end{array}$ \\
\hline General political ideology & $\begin{array}{c}0.03 \\
(0.72)\end{array}$ & $\begin{array}{c}0.41 \\
(0.76)\end{array}$ & $\begin{array}{l}-0.01 \\
(0.41)\end{array}$ & $\begin{array}{c}0.01 \\
(0.47)\end{array}$ & $\begin{array}{c}-1.53^{*} \\
(0.67)\end{array}$ & $\begin{array}{c}-2.07^{*} \\
(0.97)\end{array}$ \\
\hline \multicolumn{7}{|l|}{ Region of the World } \\
\hline United States & $\begin{array}{c}-2.46^{\star} \\
(0.97)\end{array}$ & & $\begin{array}{l}-0.37 \\
(0.54)\end{array}$ & & $\begin{array}{c}0.25 \\
(0.71)\end{array}$ & $\begin{array}{c}2.09 \\
(1.20)\end{array}$ \\
\hline \multicolumn{7}{|l|}{ Controls } \\
\hline Distance: $\mathrm{H}-\mathrm{L}[\mathrm{M}]$ & $\begin{array}{l}-0.00 \\
(0.03)\end{array}$ & $\begin{array}{l}-0.03 \\
(0.04)\end{array}$ & $\begin{array}{c}0.07 \\
(0.04)\end{array}$ & $\begin{array}{c}0.04 \\
(0.05)\end{array}$ & $\begin{array}{l}-0.00 \\
(0.02)\end{array}$ & $\begin{array}{c}0.09 \\
(0.09)\end{array}$ \\
\hline Observations (In) & $\begin{array}{l}-0.05 \\
(0.20)\end{array}$ & $\begin{array}{c}0.14 \\
(0.24)\end{array}$ & $\begin{array}{l}-0.14 \\
(0.14)\end{array}$ & $\begin{array}{l}-0.06 \\
(0.19)\end{array}$ & $\begin{array}{c}-0.58^{*} \\
(0.23)\end{array}$ & $\begin{array}{c}-1.53^{*} \\
(0.41)\end{array}$ \\
\hline Preference divergence & $\begin{array}{c}1.71^{*} \\
(0.65)\end{array}$ & $\begin{array}{l}2.03^{*} \\
(0.71)\end{array}$ & $\begin{array}{c}1.91^{*} \\
(0.62)\end{array}$ & $\begin{array}{c}1.73^{\star} \\
(0.65)\end{array}$ & $\begin{array}{c}1.06 \\
(0.81)\end{array}$ & $\begin{array}{l}-0.75 \\
(1.04)\end{array}$ \\
\hline \multicolumn{7}{|l|}{ Random Effects } \\
\hline Study-level variance & $\begin{array}{c}4.55^{\star} \\
(1.94)\end{array}$ & $\begin{array}{l}5.81^{\star} \\
(2.72)\end{array}$ & $\begin{array}{c}0.15 \\
(0.17)\end{array}$ & $\begin{array}{c}0.31 \\
(0.29)\end{array}$ & $\begin{array}{c}0.27 \\
(0.38)\end{array}$ & $\begin{array}{c}0.66 \\
(0.90)\end{array}$ \\
\hline $\mathrm{N}$ & 254 & 206 & 200 & 176 & 308 & 232 \\
\hline $\mathrm{N}$ of Studies & 24 & 16 & 20 & 15 & 24 & 20 \\
\hline Log Likelihood & -296.6 & -258.7 & -308.3 & -266.7 & -125.4 & -75.76 \\
\hline
\end{tabular}

Note: ${ }^{*} p<0.05$. Models $1-4$ are random-effects ordered logistic regressions, in which the dependent variables are the categorical variables shown in figure 4 (with ambiguous cases separated out). Models 5-6 are random-effects logistic regressions, in which the dependent variables are dummies for whether results are ambiguous (1) or not (0). Constants are estimated for all models but suppressed in the table (for full results see online appendix B). Baseline for number of groups is one. Baseline for partisanship is overall/ not party-specific. Baseline for policy domains is unspecified/not issue-specific. Baseline for region is not the United States.

(cf. Gilens and Page 2014; Rigby and Wright 2013). If this interpretation is correct, we would expect a weaker model dependence in Europe than in the United States, because a large literature in comparative political economy has documented that the interests (as opposed to the preferences) of lower-income classes are better represented in the more generous European welfare states; that is, lower-income classes exert more influence on political outcomes in Europe compared to the United States (e.g., Huber and Stephens 2001; Iversen and Soskice 2006). ${ }^{16}$ Now, consider the alternative scenario in which the model dependence reflects some statistical issue related to the high collinearity of preferences. If this is the case, we would not expect to observe any difference in the degree of the model dependence across contexts.

It turns out that the model dependence is equally strong in and outside the United States. In both the US and comparative studies, the two most severe forms of differential responsiveness (the severe and extreme prorich bias) are twice as likely to be found when the preferences of high- and low-income groups are included in the same statistical model. This result may indicate that the multivariate model is poorly equipped to accurately capture degrees of differential responsiveness when preferences are highly correlated. Indeed, it is possible that differentials in responsiveness are generally small, but that better political information among higher-income individuals leads to less measurement error in estimates of high-income preferences (Stimson 2011). Estimates of relative representation are further biased by the extent to which information conditions how individuals adjust their preferences to the political-economic context (Elkjær 2020; Elkjær and Iversen 2020; Soroka and Wlezien 2010). In multivariate models, such biases are compounded by multicollinearity (Kalnins 2018; Winship 


\section{Figure 5}

\section{The Model Specification Is a Strong Predictor of Economic-Elite Dominance}

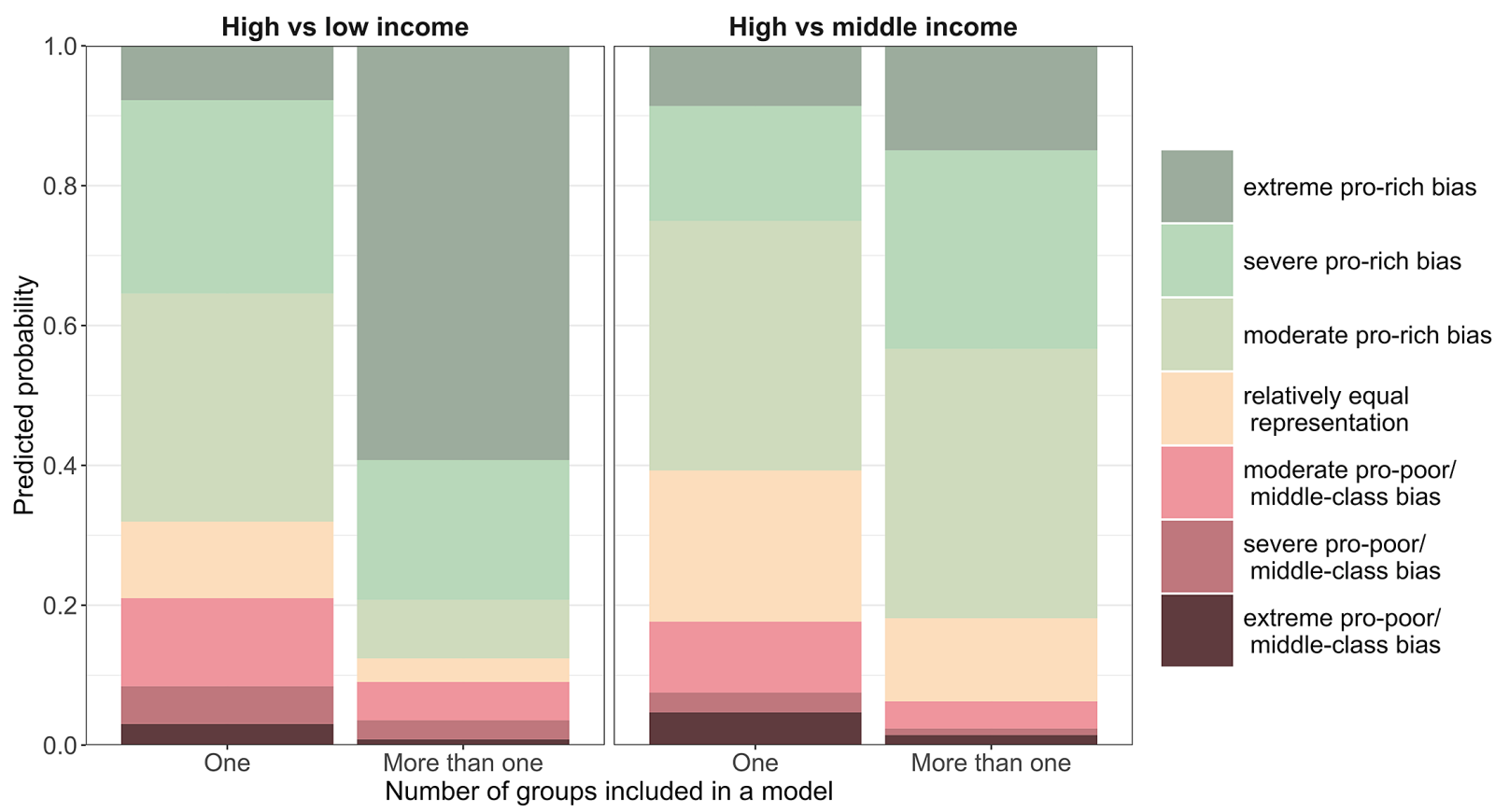

Note: The predicted probabilities can be interpreted as the predicted proportion of published findings that fall into each category of differential responsiveness accounting for other study and model characteristics.

and Western 2016), which may help explain the frequency of findings of extreme pro-rich bias in political responsiveness.

Although these results do not demonstrate that either the dominance of the rich or the nonresponsiveness of political outcomes to the preferences of the poor are statistical artifacts, the results do raise that possibility. Because the model dependence is so strong and there remains significant uncertainty about how to interpret it, it is unfortunate that more than one-third of published studies ( 9 of 25 ) rely on multivariate analysis of income-group preferences only. ${ }^{17}$ Researchers must carefully consider whether this is appropriate.

An important task for future research is to establish standards with respect to the statistical modeling and reporting of differential responsiveness, which would help improve the comparability of results across studies and clarify the normative and theoretical implications of the findings. We advise scholars to take a cautious approach and first assess differences in responsiveness by including preferences in separate models and then, if feasible, assess the results of models that include preferences simultaneously (for a good example, see Rigby and Wright 2013). It may also be fruitful to consider alternative research designs to illuminate the relative influence of different groups. One promising approach is to examine policies on which groups have opposing preferences: doing so circumvents the problems that the multivariate analysis faces and centers the analysis on policies on which politicians are forced to take sides; for good examples, see Branham, Soroka, and Wlezien (2017) and Lax, Phillips, and Zelizer (2019). On the whole, the degree of differential responsiveness remains highly contested, and it continues to be an important task to explore ways to reliably measure it.

Partisanship. The left panel of figure 6 shows that in the United States both Democrats and Republicans respond more strongly to the preferences of the rich than to those of the poor (the green shades). At the same time, the figure shows a clear indication that Democrats are more responsive to the preferences of the poor than are Republicans. In 8 of 10 cases, Republicans overrepresent the rich compared to the poor, whereas for Democrats it is in roughly 2 of 3 cases. Moreover, a study is more than twice as likely to find that Democrats overrepresent the poor compared to Republicans (the red shades: .27 vs .12).

But whereas partisanship matters for the relative representation of the poor and the rich, the right panel of figure 6 shows that partisanship does not condition findings of differential responsiveness between middle- and highincome groups. Here we see virtually no differences in results depending on the partisanship of the representative or government. In all cases, the rich appear vastly overrepresented compared to the middle class. 


\section{Figure 6}

\section{Democrats Represent the Poor Relatively Better than Republicans}

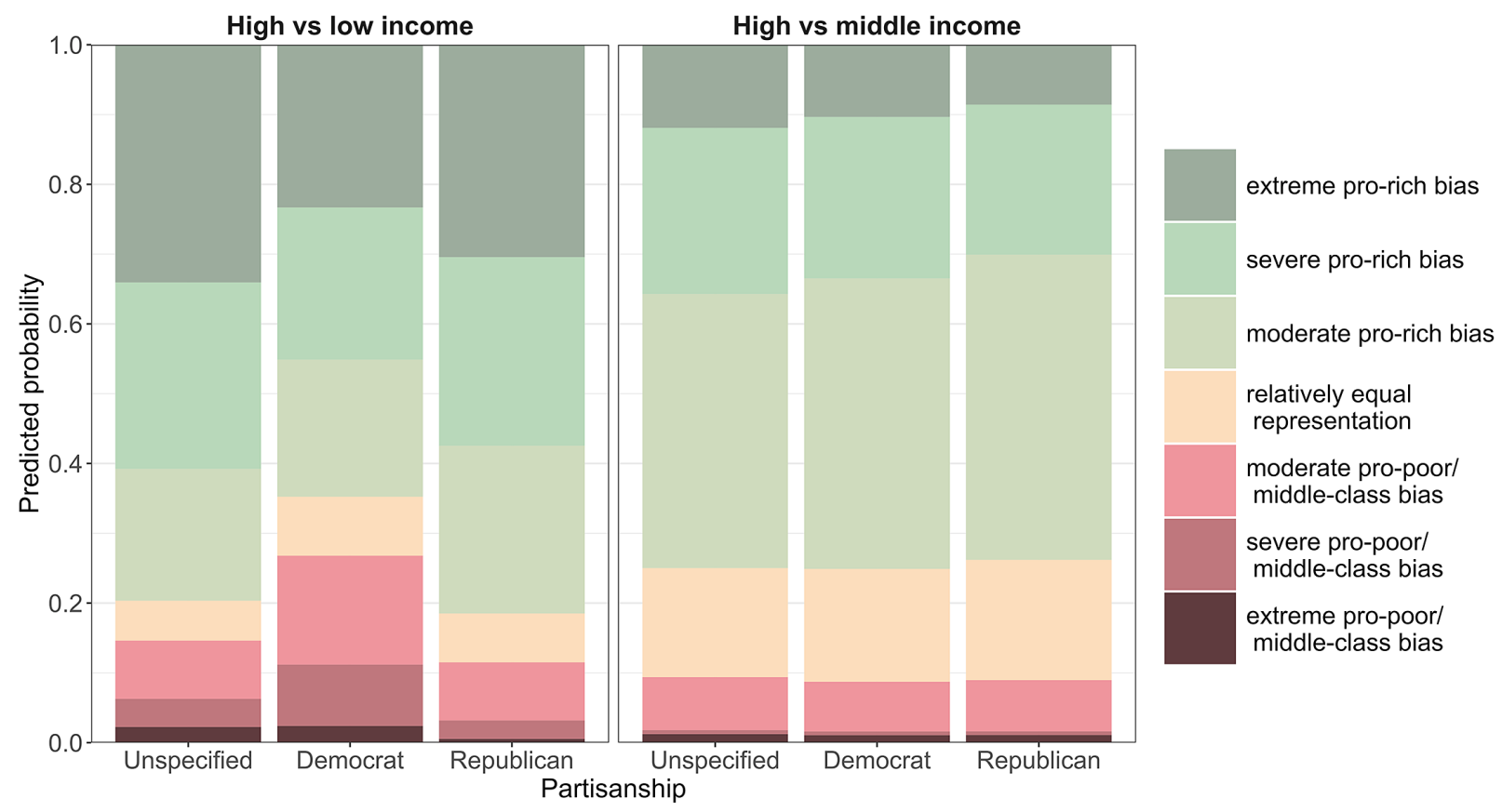

Note: The predicted probabilities can be interpreted as the predicted proportion of published findings that fall into each category of differential responsiveness accounting for other study and model characteristics.

How do these results line up with the theoretical expectations? The results for the high-low income comparison are partly consistent with partisan theories of democracy in that who is in office clearly conditions the relative representation of the groups; yet, they are not fully consistent with such theories because even Democrats appear to overrepresent the rich. The results for the highmiddle income comparison are inconsistent with most standard theories of democracy.

Even though these results suggest that income may matter more for political representation than partisanship, it would be a mistake to conclusively say so. One important limitation of the quantitative review is that it includes only studies that analyze one type of political representation (responsiveness). Recent studies that use alternative measures of representation find the opposite pattern in which partisanship is more important for representation than income (Lax, Phillips, and Zelizer 2019; Maks-Solomon and Rigby 2020). Overall then, it seems certain that partisanship is important for explaining differences in political representation; the question of how important remains unsettled.

For this reason, disentangling the impact of partisanship remains an important research agenda. It is puzzling that the observed effects of partisanship are not stronger and that partisanship appears to matter only for the relative representation of high- and low-income groups. Future research should continue to examine the importance of partisanship relative to income and, in doing so, focus on the comparison between high- and middle-income groups, which has received less attention than that between highand low-income groups. It cannot be ruled out that the greater emphasis on the rich-poor comparison highlights the importance of partisanship for explaining differences in representation between the rich and the poor, while leaving similar differences between the middle and the rich undocumented. Future research should also continue to examine the conditions under which policy makers of different partisan stripes are more likely to respond to the preferences of different income groups (e.g., Rigby and Wright 2013; Wright and Rigby 2020). Finally, partisanship should be especially high on the agenda for comparative scholars, because the importance of partisanship for differentials in political responsiveness is almost entirely unexplored outside the United States.

Policy Domain. Differences in published results across policy domains are statistically insignificant (see table 1), but the distributions of probabilities shown in figure 7 suggest that studies observe greater differentials in responsiveness on economic issues when comparing the rich and the poor; the probability of observing the extreme pro-rich bias is especially high. This result, however, is driven solely by the comparative studies. In the United States there are no stark differences in results across domains; if anything, the differentials appear slightly smaller on economic issues (see online appendix E). The differences across domains are also 


\section{Figure 7}

\section{No Systematic Differences in Findings across Policy Domains}

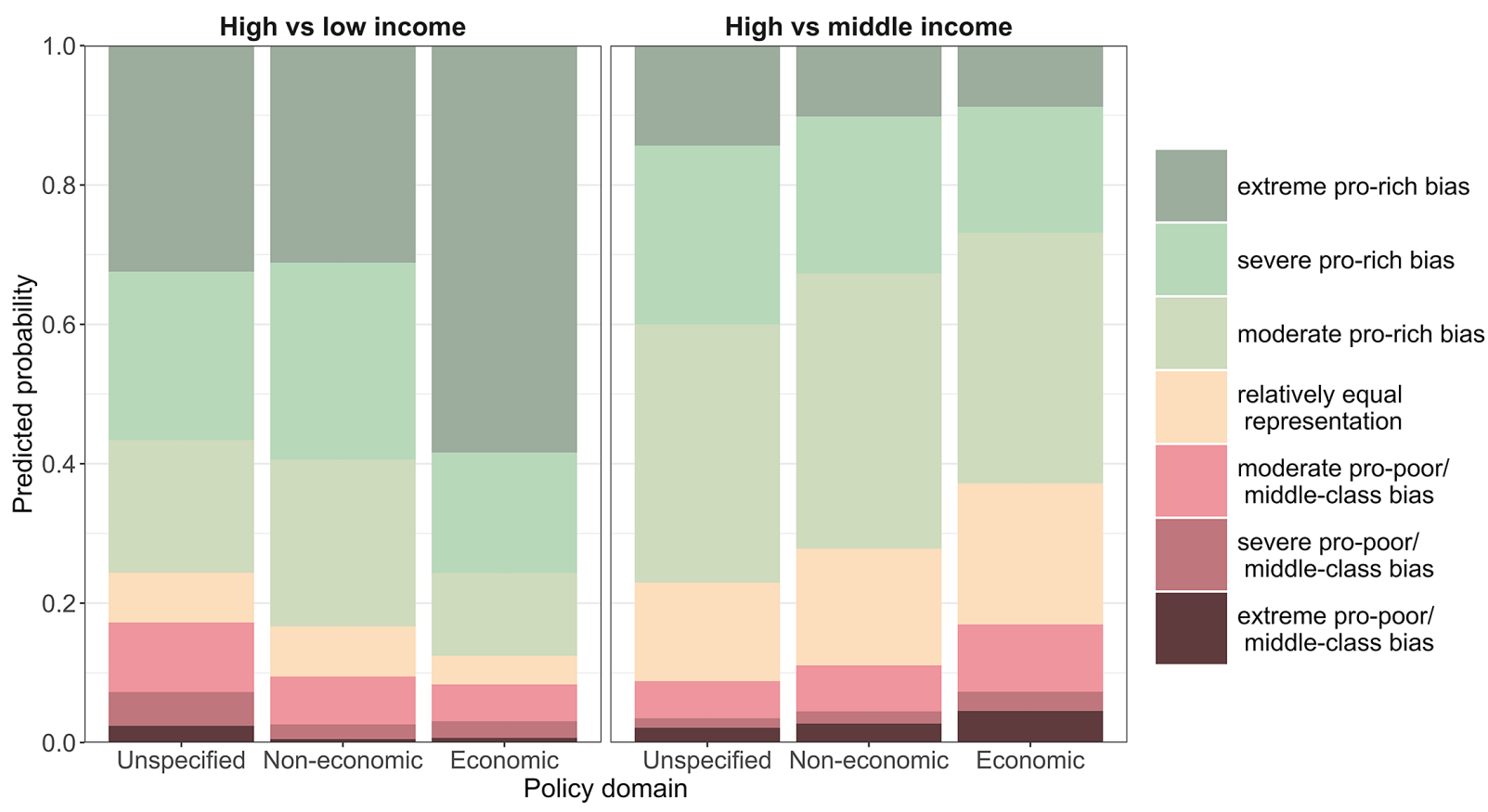

Note: The predicted probabilities can be interpreted as the predicted proportion of published findings that fall into each category of differential responsiveness accounting for other study and model characteristics.

insignificant when comparing the middle and the rich, but here published research indicates that middle-class preferences may be slightly better represented on economic issues.

How may these results help us understand the underlying mechanisms? If crony capitalism and money in politics were driving the observed differentials in responsiveness, creating a vicious cycle between economic inequality and political inequality, we would expect representation to be more unequal on economic domains, because they directly affect the distribution of income and wealth. Although we observe some indication of this pattern when comparing the rich and the poor, it is driven solely by the comparative studies, and the differences are insignificant. Moreover, the middle class actually appears to be doing somewhat better on economic issues. These findings suggest that the driver of published results is not simply a story about crony capitalism and money in politics. Rather, it suggests the presence of a generic driver that affects responsiveness similarly across domains.

Level of Aggregation of Policies and Preferences. Figure 8 shows that differentials in responsiveness appear slightly weaker on specific policies, compared to aggregate measures of political outcomes. But as for policy domains, the differences in results across levels of aggregation are statistically insignificant (see table 1). These patterns are inconsistent with the notion that the rich and organized interests exert greater political influence on more specific policies for which visibility and public attention are low. Of course, the results do not refute this argument, but they indicate that it may not be driving the published results. Rather, the results may again point to the presence of a generic driver.

Region. The comparison between the high- and lowincome groups in the left panel of figure 9 shows that observed differentials in political responsiveness are starker outside the United States than in the country. In about 7 of 10 cases, comparative studies find the extreme prorich bias, in which political outcomes reflect the preferences of the rich but go against those of the poor. The extreme pro-rich bias is also observed most frequently in the United States but in just 3 of 10 cases. Moreover, studies of the United States are more than four times as likely as comparative studies to observe a pro-poor bias (.16 vs .034). The right panel of figure 9 shows that findings of differential responsiveness between high- and middle-income groups are virtually identical in and outside the United States, suggesting that representational disparities between middle- and upper-income classes are unrelated to the political-economic context.

Considering that the countries studied in the comparative literature (Canada, Denmark, Germany, Netherlands, Switzerland, and developed democracies more generally) 


\section{Figure 8}

\section{No Significant Differences in Findings across Different Levels of Aggregation}

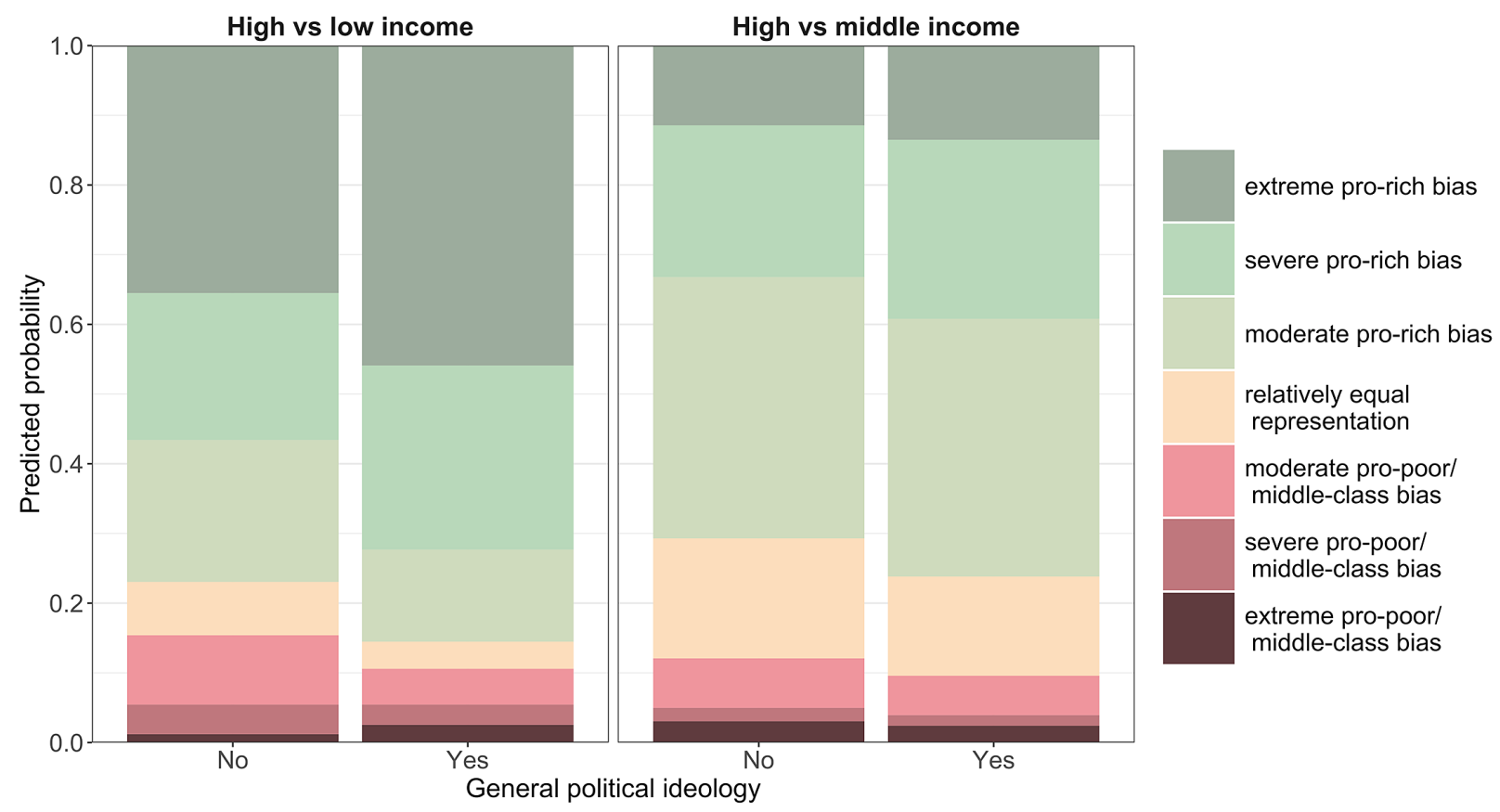

Note: The predicted probabilities can be interpreted as the predicted proportion of published findings that fall into each category of differential responsiveness accounting for other study and model characteristics.

\section{Figure 9}

\section{Comparative Studies Find Starker Differentials in Political Responsiveness than Studies of the} United States

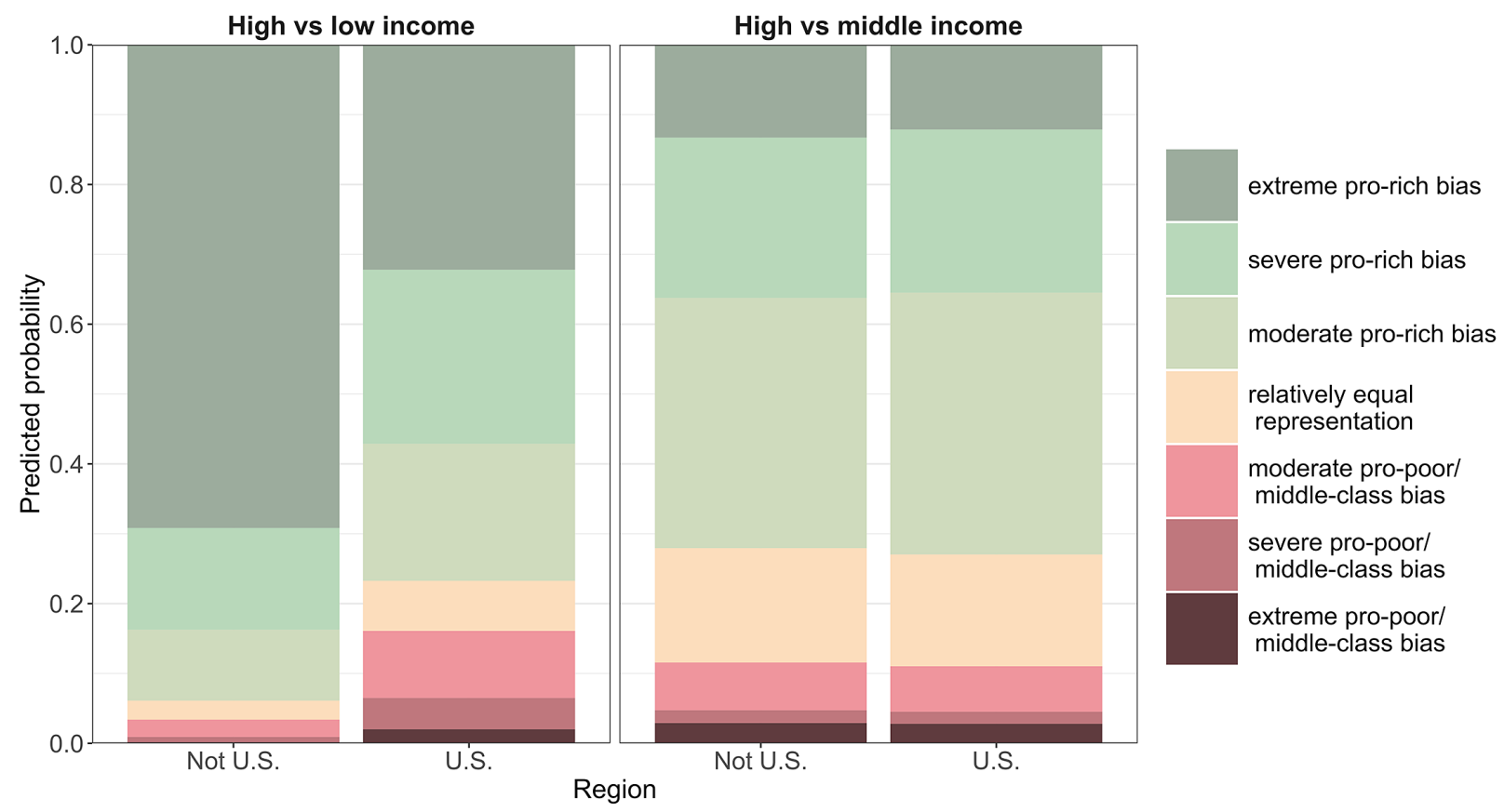

Note: The predicted probabilities can be interpreted as the predicted proportion of published findings that fall into each category of differential responsiveness accounting for other study and model characteristics. 
have lower levels of economic inequality, stronger left parties and labor unions, higher turnout rates, and less money in politics than the United States, these results are puzzling. They go against conjectures that the United States might be a unique case regarding political inequality. They also challenge long-standing theories in comparative political economy, which explain the more egalitarian political outcomes in Europe partly as a function of political and economic institutions, a stronger working class, and greater political influence of lowincome groups (e.g., Hall and Soskice 2001; Huber and Stephens 2001; Iversen and Soskice 2006).

The lack of theoretically meaningful variation in results across contexts may help us understand the underlying mechanisms. US scholars have proposed that differentials in responsiveness are driven by money in politics, a descriptive overrepresentation of the rich, or inequalities in the organization of interest groups (Bartels 2008; Becher and Stegmueller 2021; Carnes 2013; Gilens 2015a). In Europe, where private campaign contributions are significantly smaller, scholars have highlighted disparities in turnout, descriptive representation, and interestgroup mobilization as potential mechanisms (Elsässer, Hense, and Schäfer 2018; Peters and Ensink 2015; Schakel 2019). All of these mechanisms can be (and have been) theoretically connected to varying degrees of unequal representation. Yet they are all unable to explain why differentials in responsiveness appear more (or even equally) pronounced in Europe compared to the United States. The system of private campaign finance is unique to the United States, and in most European countries, organized labor groups are significantly stronger and turnout is considerably higher than in the United States. Moreover, although the poor tend to be underrepresented in European parliaments, politicians do not come from the absolute top echelons of the income distribution, which means that a descriptive underrepresentation of the poor cannot explain why middle-income groups appear similarly poorly represented compared to high-income groups in both the United States and Europe. We are thus left with a set of potential explanations that, although consistent with some degree of unequal representation in any individual country, cannot explain the similarity of findings across countries. Why social Europe appears to experience more unequal representation than liberal America is puzzling and warrants further scrutiny.

One suggested mechanism, consistent with the observed patterns of differential responsiveness, is disparities in information across income groups. Better informed individuals express preferences that are more consistent with the voting behavior of representatives in the US Congress (Hill and Huber 2019). And better information among high-income individuals is arguably what is driving the findings across countries and in Denmark (Elkjær 2020; Elkjær and Iversen 2020). One potential direction for future research is to assess the degree to which differentials in responsiveness can be explained by informational asymmetries, whether the explanatory power of this argument varies across contexts, and how equal responsiveness is once informational asymmetries are accounted for.

Regardless of the role of information, we encourage future research to take note of the similarity of findings across countries, which indicates the presence of (partly) similar underlying mechanisms and can help researchers rule out explanations. Thus, the US and comparative literatures can benefit from greater attentiveness to each other. We also encourage scholars to take seriously the observed pattern of unequal responsiveness when forming theoretical propositions. For instance, published findings are not consistent with disparities in turnout in either the United States or Europe because they would only be able to explain less severe forms of differential responsiveness: they cannot explain why the poor so often seem to be completely ignored or why the rich appear so much better represented than the middle class. Accounts seeking to explain unequal representation should be consistent with the empirically observed patterns.

\section{Conclusion}

The systematic review of published research has shown that there is considerable variation in results across models and studies. In fact, the entire palette of possible findings is represented in the published literature-some studies find an overrepresentation of the rich, others of the middle class, and still others of the poor, and added to this are several cases of both equal representation and nonresponsiveness. At the same time, the review found little (theoretically relevant) variation in results across contexts. The partisanship of the representative/government matters less than standard theories of democracy would predict, the variation in results between the United States and Europe is theoretically puzzling, and there is no systematic variation across either policy domains or political outcomes. These findings raise two seemingly contradictory questions: Why do studies reach so different conclusions, and what is driving the similarity in published results across domains, outcomes, parties, and countries?

Because published studies come to vastly different conclusions, it is difficult to give a full accounting of the divergence in results. The review does, however, highlight some possible explanations. Our quantitative analysis established that the model specification is the strongest driver of severe forms of differential responsiveness. Studies that rely on multivariate analysis of income-group preferences find starker differentials in political responsiveness than studies that (also) rely on bivariate analysis. Another important distinction is whether a study examines short-term changes in policies, which better reflect the preferences of the rich, or long-run levels of policies, which 
better reflect the preferences of the middle class. Finally, the overrepresentation of the poor may partly be explained by partisan differences, because Democrats represent the preferences of the poor better than Republicans. Yet, these factors can only partly account for differences in published results; much of the variation reflects more fundamental differences across studies.

Although the analysis showed considerable divergence in results across studies, it also found little (theoretically relevant) variation across contexts. The most puzzling finding is that comparative studies find starker differentials in responsiveness than those of the United States. This finding is likely related to model specification choices, because comparative studies rely more heavily on multivariate analysis, which, as we have seen, produces anticonservative estimates of differentials in responsiveness. Specification choices, however, are unlikely to explain why lower-income groups do not appear to be better represented in Europe compared to the United States, as standard theories would suggest.

The similarity of published results across countries, domains, outcomes, and parties suggests that the driver is generic. Crony capitalism and money in politics would suggest stronger differentials on specific economic policies in the United States, patterns that we do not observe. Disparities in voter turnout predict similar patterns across domains and outcomes, but not across countries. Inequalities in interest-group mobilization would suggest starker differentials in the United States, where organized labor is weaker than in Europe, but published research finds the opposite pattern. And although party politics appears important, the observed differences in results across Republicans and Democrats are smaller than partisan theories of democracy would predict.

One generic, and increasingly popular, explanation of published results is a descriptive underrepresentation of the poor and uneducated in local and national legislatures. That more affluent and better-educated politicians may not fully understand the circumstances and preferences of the poor can potentially explain why responsiveness to the preferences of the poor is so low across all contexts. But whereas the poor and uneducated are underrepresented in most legislatures, the educated middle class is well represented in most European legislatures. Underrepresentation of the poor and uneducated, therefore, cannot explain why the educated middle class appears so poorly represented in both the United States and Europe, raising questions about the overall explanatory power of this argument.

Disparities in information and its effect on preferences and voting behavior are more consistent with published results. Low levels of information among the poor may dilute the clarity of their preferences, making it harder for politicians to respond meaningfully to their preferences. They can also lead to votes for parties that do not represent their interests (Erikson 2015). Another possibility is that the poor, due to a lack of information or preference manipulation, sometimes support policies that benefit the rich (Bartels 2008). Yet, given the frequency of findings of nonresponsiveness of policies to the preferences of the poor, it seems unlikely that it is happening on a grand scale.

Although these effects of information could cause inequalities in substantive political representation, information also has the potential to cause biased estimates. Similar findings across contexts are consistent with differential measurement error in income-group preferences (Stimson 2011) and the argument that the rich adjust their preferences more strongly to the political-economic context than do lower income classes (Elkjær 2020; Elkjær and Iversen 2020; Soroka and Wlezien 2010). And perhaps revealingly, studies tend to find similar differences in political responsiveness across other correlates of information than income, such as across educational and occupational groups (Elsässer, Hense, and Schäfer 2018; Soroka and Wlezien 2010). What exactly is driving the published results remains an open question.

Because the theoretical and democratic implications of the results depend on the drivers, a better understanding of the underlying mechanisms is critical to advancing the literature and our understanding of democracy. So far, scholars have focused predominantly on documenting differentials in responsiveness; a major task remains to fully understand the underlying mechanisms. We hope that this review will prove helpful in that regard.

\section{Acknowledgements}

For valuable feedback on the set of studies included in the systematic review and for their comments on previous versions of the article, we thank Patrick Flavin, Christoffer Florczak, Jesper Hansen, Patricia Kirkland, Robert Klemmensen, Jennifer Oser, Mikael Persson, Daeun Song, Wouter Schakel, Dennis Spies, Pieter Vanhuysse, Christopher Wlezien, and participants at the Annual Meeting of the Midwest Political Science Association (2021). We would also like to thank the editors of Perspectives on Politics and the five anonymous reviewers for their many helpful comments and suggestions. For research assistance, we thank Camilla Lund Knudsen. Elkjær acknowledges funding from the European Research Council (ERC) under the European Union's Horizon 2020 research and innovation programme, grant agreement no. 724949 . The ERC project code for this project is WEALTHPOL.

Klitgaard acknowledges funding from the Danish Council for Independent Research, grant no. 8019-00053B.

\section{Supplementary Materials}

To view supplementary material for this article, please visit http://dx.doi.org/10.1017/S1537592721002188. 


\section{Notes}

1 www.newyorker.com/news/john-cassidy/is-americaan-oligarchy.

2 https://twitter.com/VandyPoliSci/sta tus $/ 1255339837193846784$ ? $s=20$.

3 The quote is from a Monkey Cage blog post by Larry Bartels: www.washingtonpost.com/news/monkeycage/wp/2014/04/08/rich-people-rule.

4 Because comparative studies have devoted little attention to partisanship, we cannot examine its impact outside the United States.

5 In their simulations, Elkjær and Iversen (2020) illustrate the issue in the context of standard countercyclical fiscal policies. They show that even if spending perfectly matches the long-run interests of the middle class, it seems that only the rich influence spending. The reason is that the rich are better informed about the need for countercyclical spending and therefore express more countercyclical preferences.

6 Elkjær (2020) tests the example of countercyclical spending used in the simulations of Elkjær and Iversen (2020) and finds that the poor express stronger procyclical preferences than the rich. When spending adjusts countercyclically to the business cycle, these short-term changes will therefore better reflect the preferences of the rich, even though they are also in the interests of the poor.

7 Because the literature emerged after the APSA Task Force on Inequality and American Democracy concluded its work (APSA 2004), we consider 2004 to be the starting year of the literature.

8 Although Achen (1978) also considers the intercept as part of responsiveness, empirical researchers focus on the slope coefficient. That is because preferences and outcomes are rarely measured on the same scale, complicating the use of the intercept to assess how closely preferences match outcomes (Wlezien 2017, 563).

9 Several studies divide respondents into groups (most often terciles) in which case we code the midpoint of the group's percentile position as its location in the income distribution.

10 As in figure 3, if a study reports the coefficients of more than three income groups, we compare the coefficients of the groups with the lowest, median, and highest income.

11 Formally the coding of the variables (High_Low and High_Middle) can be written as

High_Low[Middle] $= \begin{cases}\text { 1: extreme pro-poor[middle-class] bias } & \text { if } \beta_{H}<0<\beta_{L[M]} \\ \text { 2: severe pro-poor[middle-class] bias } & \text { if } \beta_{H} / \beta_{L[M]} \leq 1 / 2 \\ \text { 3: moderate pro-poor[middle-class] bias } & \text { if } 1 / 2<\beta_{H} / \beta_{L[M]} \leq 0.85 \\ \text { 4: relatively equal representation } & \text { if } 0.85<\beta_{H} / \beta_{L[M]}<1.15 \\ \text { 5: moderate pro-rich bias } & \text { if } 1.15 \leq \beta_{H} / \beta_{L[M]}<2 \\ \text { 6: severe pro-rich bias } & \text { if } 2 \leq \beta_{H} / \beta_{L[M]} \\ \text { 7: extreme pro-rich bias } & \text { if } \beta_{L[M]}<0<\beta_{H} \\ \text { Amb: ambiguous results } & \text { if } \beta_{L[M]}<0 \text { AND } \beta_{H}<0 \text { OR } \\ & .1<P_{\beta_{L[M]}} \text { AND .1 } 1<P_{\beta_{H}},\end{cases}$

where $\beta_{H}$ refers to coefficients of high-income preferences and $\beta_{L[M]}$ to coefficients of low- or middleincome preferences. $P_{\beta C}$ is the $p$-value of a coefficient of income-class preferences $C$. Because many studies rely on small samples, we use $P<.1$ as the significance threshold.

12 The results are robust to using fixed-effects models (see online appendix C).

13 Ideally, we would treat preference divergence as a substantive variable, but because only a few studies, most notably Gilens (2012), use this empirical strategy we cannot provide reliable quantitative comparisons of how published results differ across degrees of preference divergence.

14 Descriptive statistics of the independent variables are included in online appendix D.

15 Readers mainly interested in the United States can find a full analysis of the US studies in online appendix E.

16 The distinction between the preferences and interests of individuals has been made by political theorists over several centuries. For a detailed discussion about the distinction, see Pitkin (1967, especially chaps. 7-9).

17 By contrast, just 4 of 25 studies rely on bivariate analysis of income-group preferences only, and 12 of 25 studies rely on both bivariate and multivariate analysis.

\section{References}

Achen, Christopher H. 1977. "Measuring Representation: Perils of the Correlation Coefficient." American Journal of Political Science 21 (4): 805-15.

Achen, Christopher. 1978. "Measuring Representation." American Journal of Political Science 22 (3): 475-510.

American Political Science Association. 2004. "American Democracy in an Age of Rising Inequality." Perspectives on Politics 2 (4): 651-66.

Bartels, Larry M. 2008. Unequal Democracy: The Political Economy of the New Gilded Age. New York: Russell Sage Foundation.

Bartels, Larry M. 2017. "Political Inequality in Affluent Democracies: The Social Welfare Deficit." CSDI Working Paper 5-2017. Vanderbilt University. https:// www.vanderbilt.edu/csdi/includes/Working_Paper_ 5_2017.pdf.

Bashir, Omar S. 2015. "Testing Inferences about American Politics: A Review of the 'Oligarchy' Result.” Research \& Politics 2 (4): 1-7.

Becher, Michael, and Daniel Stegmueller. 2021. "Curbing Unequal Representation: The Impact of Labor Unions on Legislative Responsiveness in the US Congress." Perspectives on Politics 19 (1): 92-109.

Bhatti, Yosef, and Robert Erikson. 2011. "How Poorly Are the Poor Represented in the U.S. Senate?" In Who 
Gets Represented? ed. Peter K. Enns and Christopher Wlezien, 223-46. New York: Russell Sage Foundation.

Branham, Alexander, Stuart N. Soroka, and Chistopher Wlezien. 2017. "When Do the Rich Win?” Political Science Quarterly 132 (1): 43-62.

Brunner, Eric, Stephen L. Ross, and Ebonya Washington. 2013. "Does Less Income Mean Less Representation?" American Economic Journal: Economic Policy 5 (2): 53-76.

Carnes, Nicholas. 2013. White-Collar Government: The Hidden Role of Class in Economic Policy Making. Chicago: University of Chicago Press.

Elkjær, Mads Andreas. 2020. "What Drives Unequal Policy Responsiveness? Assessing the Role of Informational Asymmetries in Economic Policy-Making." Comparative Political Studies 53 (14): 2213-45.

Elkjær, Mads Andreas, and Torben Iversen. 2020. "The Political Representation of Economic Interests: Subversion of Democracy or Middle-Class Supremacy?" World Politics 72 (2): 254-90.

Ellis, Christopher. 2013. "Social Context and Economic Biases in Representation." Journal of Politics 75 (3): 773-86.

Elsässer, Lea, Svenja Hense, and Armin Schäfer. 2018. "Government of the People, by the Elite, for the Rich: Unequal Responsiveness in an Unlikely Case." MPIfG Discussion Paper 18/5. https://www.mpifg.de/pu/ mpifg_dp/2018/dp18-5.pdf.

Enns, Peter K. 2015. "Relative Policy Support and Coincidental Representation." Perspectives on Politics 13 (4): 1053-64.

Erikson, Robert S. 2015. "Income Inequality and Policy Responsiveness." Annual Review of Political Science 18 (1): 11-29.

Flavin, Patrick. 2012a. "Does Higher Voter Turnout among the Poor Lead to More Equal Policy Representation?” Social Science Journal 49 (4): 405-12.

Flavin, Patrick. 2012b. "Income Inequality and Policy Representation in the American States." American Politics Research 40 (1): 29-59.

Gilens, Martin. 2005. "Inequality and Democratic Responsiveness." Public Opinion Quarterly 69 (5): 778- 96.

Gilens, Martin. 2009. "Preference Gaps and Inequality in Representation." PS_Political Science \& Politics 42 (2): 335-41.

Gilens, Martin. 2012. Affluence and Influence: Economic Inequality and Political Power in America. New York: Russell Sage Foundation.

Gilens, Martin. 2015a. "Descriptive Representation, Money, and Political Inequality in the United States." Swiss Political Science Review 21 (2): 222-28.

Gilens, Martin. 2015b. "The Insufficiency of 'Democracy by Coincidence’: A Response to Peter K. Enns.” Perspectives on Politics 13 (4): 1065-71.
Gilens, Martin. 2016. “Simulating Representation: The Devil's in the Detail." Research \& Politics 2 (4): 1-3. Gilens, Martin, and Benjamin I. Page. 2014. "Testing Theories of American Politics: Elites, Interest Groups, and Average Citizens." Perspectives on Politics 12 (3): 564-81.

Hacker, Jacob, and Paul Pierson. 2010. "Winner-Take-All Politics: Public Policy, Political Organization, and the Precipitous Rise of Top Incomes in the United States." Politics \& Society 38 (2): 152-204.

Hall, Peter A., and David Soskice. 2001. Varieties of Capitalism: The Institutional Foundations of Comparative Advantage. Oxford: Oxford University Press.

Hayes, Thomas. J. 2012. "Responsiveness in an Era of Inequality: The Case of the U.S. Senate." Political Research Quarterly 66 (3): 585-99.

Hill, Seth J., and Gregory A. Huber. 2019. "On the Meaning of Survey Reports of Roll-Call 'Votes.' American Journal of Political Science 63 (3): 611-25.

Huber, Evelyn, and Stephens, John. 2001. Development and Crisis of the Welfare State: Parties and Politics in Global Markets. Chicago: University of Chicago Press.

Iversen, Torben, and David Soskice. 2006. "Electoral Institutions and the Politics of Coalitions: Why Some Democracies Redistribute More than Others." American Political Science Review 100 (2): 165-81.

Kalnins, Arturs. 2018. "Multicollinearity: How Common Factors Cause Type 1 Errors in Multivariate Regression." Strategic Management Journal 39 (8): 2362-85.

Lax, Jeffrey R., Justin H. Phillips, and Adam Zelizer. 2019. "The Party or the Purse? Unequal Representation in the US Senate." American Political Science Review 113 (4): 917-40.

Liberati, Alessandro, Douglas G. Altman, Jennifer Tetzlaff, Cynthia Mulrow, Peter C. Gøtzsche, John P. A. Ioannidis, Mike Clarke, et al. 2009. "The PRISMA Statement for Reporting Systematic Reviews and Meta-Analyses of Studies that Evaluate Health Care Interventions: Explanation and Elaboration." PLoS Medicine 6 (7): 1-28.

Maks-Solomon, Cory, and Elizabeth Rigby. 2020. "Are Democrats Really the Party of the Poor? Partisanship, Class, and Representation in the U.S. Senate." Political Research Quarterly 73 (4): 848-65.

Page, Benjamin I., Larry M. Bartels, and Jason Seawright. 2013. "Democracy and the Policy Preferences of Wealthy Americans." Perspectives on Politics 11 (1): 51-73.

Peters, Yvette, and Sanders Ensink. 2015. "Differential Responsiveness in Europe: The Effects of Preference Difference and Electoral Participation." West European Politics 38 (3): 577-600. 
Pitkin, Hannah F. 1967. The Concept of Representation Berkeley: University of California Press.

Rhodes, Jesse H., and Brian F. Schaffner. 2017. "Testing Models of Unequal Representation: Democratic Populists and Republican Oligarchs?" Quarterly Journal of Political Science 12 (2): 185-204.

Rigby, Elizabeth, and Gerald C. Wright. 2011. "Whose Statehouse Democracy? Policy Responsiveness to Poor versus Rich Constituents in Poor versus Rich States." In Who Gets Represented? ed. Peter K. Enns and Christopher Wlezien, 189-222. New York: Russell Sage Foundation.

Rigby, Elizabeth, and Gerald C. Wright. 2013. "Political Parties and Representation of the Poor in the American States." American Journal of Political Science 57 (3): 552-65.

Schakel, Wouter. 2019. "Unequal Policy Responsiveness in the Netherlands." Socio-Economic Review 1-21.

Schakel, Wouter, Brian Burgoon, and Armen Hakhverdian. 2020. "Real but Unequal Representation in Welfare State Reform." Politics and Society 48 (1): 131-63.

Soroka, Stuart N., and Christopher Wlezien. 2008. "On the Limits to Inequality in Representation." PS: Political Science \& Politics 41 (2): 319-27.

Soroka, Stuart N., and Christopher Wlezien. 2010. Degrees of Democracy: Politics, Public Opinion, and Policy. New York: Cambridge University Press.

Stadelmann, David, Marco Portmann, and Reiner Eichenberger. 2015. "Income and Policy Choices:
Evidence from Parliamentary Decisions and Referenda." Economics Letters 135: 117-20.

Stimson, James A. 2011. "The Issues of Representation." In Who Gets Represented? ed. Peter K. Enns and Christopher Wlezien, 347-60. New York: Russell Sage Foundation.

Tausanovitch, Chris. 2016. "Income, Ideology, and Representation." RSF: The Russell Sage Foundation Journal of the Social Sciences 2 (7): 33-50.

Ura, Joseph Daniel, and Christopher R. Ellis. 2008. "Income, Preferences, and the Dynamics of Policy Responsiveness." PS: Political Science \& Politics 41 (4): 785-94.

Winship, Christopher, and Bruce Western. 2016. "Multicollinearity and Model Misspecification." Sociological Science 3: 627-49.

Wlezien, Christopher. 2017. "Public Opinion and Policy Representation: On Conceptualization, Measurement, and Interpretation." Policy Studies Journal 45 (4): 561-82.

Wlezien, Christopher, and Stuart N. Soroka. 2011. "Inequality in Policy Responsiveness?" In Who Gets Represented? ed. Peter K. Enns and Christopher Wlezien, 285-310. New York: Russell Sage Foundation.

Wright, Gerald C., and Elizabeth Rigby. 2020. "Income Inequality and State Parties: Who Gets Represented?" State Politics and Policy Quarterly 20 (4): 395-415. 